\title{
Long-Range Real Migration of Implantable Cardioverter Defibrillator Lead
}

\author{
Andreas Keyser ${ }^{1} \quad$ Harald Brodoefel $^{2} \quad$ Christof Schmid $^{1}$ \\ ${ }^{1}$ Cardiothoracic Surgery, University Medical Center Regensburg, \\ Regensburg, Germany \\ 2Diagnostic Radiology, University Medical Center Regensburg, \\ Regensburg, Germany \\ Thorac Cardiovasc Surg Rep 2016;5:62-64.
}

Address for correspondence Andreas Keyser, MD, Cardiothoracic Surgery, University Medical Center Regensburg, Franz-Josef-Strauß-Allee 11, Regensburg 93042, Germany (e-mail: andreas.keyser@ukr.de).

\begin{abstract}
The need for pacemaker and implantable cardioverter defibrillator (ICD) lead revisions and extractions is steadily increasing. Despite the lack of representative studies, the risk

Keywords

- implantable cardioverter defibrillator

- lead extraction

- transmural migration of lead extraction is frequently considered to be lower than leaving nonfunctional leads in situ.

We report the case of a patient who was referred to our institution for exchange of a malfunctioning ICD lead. The diagnostic work-up revealed a long-segment transmural migration of the ICD lead at the site of the subclavian and innominate vein. Due to the unpredictable risk of vein perforation, we abandoned the extraction procedure.
\end{abstract}

\section{Background}

The need for pacemaker and implantable cardioverter defibrillator (ICD) lead revisions and extractions is steadily increasing. ${ }^{1,2}$ With increasing confidence in lead extraction techniques, the risk of complications when extracting superfluous leads may be considered to be comparable to leaving nonfunctional leads in situ. ${ }^{1,3}$ Representative studies are lacking. The reported complication rate associated with these procedures is estimated to be $1.7 \%{ }^{4} \mathrm{~A}$ life-threatening complication during lead extraction resulting in pleural and/or pericardial effusion and tamponade is transmural migration of the lead. ${ }^{5}$

We report the case of a young male patient who was transferred to our institution for ICD lead exchange. Diagnostic work-up revealed a long-segment transmural migration of the ICD lead at the site of the subclavian and innominate vein.

\section{Case}

A 21-year-old male patient with a history of Brugada syndrome (idiopathic ventricular fibrillation) was referred to our institution for right ventricular ICD lead exchange, which had been implanted at the age of 7 years. An ICD lead (Medtronic
Sprint [Minneapolis, Minnesota, United States] [sprint fidelis single coil defibrillation lead 6932]) had been implanted via lateral puncture of the left subclavian vein in Seldinger technique according to the operation record then. He had had a device exchange 6 years later with documented multiple adequate shocks for ventricular fibrillation. Now, 8 years later, he experienced an inappropriate shock due to lead malfunction in consequence of lead fracture. In addition, the ICD battery had reached replacement criteria. The patient presented no further conspicuities; tricuspid valve insufficiency was excluded by echocardiography. With regard to patient age and after balancing the risk/benefit ratio, a lead exchange with removal of the nonfunctional lead was aspired. In preparation for lead extraction, a chest X-ray was obtained ( - Fig. 1). Due to the atypical lead position of the stretched transvenous ICD lead suspicious for transmural lead migration, a phlebography was added. Computed tomography was not performed to limit the radiation exposure (-Fig. 2). Phlebography revealed long-segment real transmural migration of the ICD lead at the site of the subclavian and innominate vein. Therefore, we refrained from lead extraction and left the malfunctioning ICD lead in situ ( - Fig. 3). The left subclavian vein was punctured laterally under ultrasound control. A new lead was implanted using an introducer received

July 31,2015

accepted after revision

September 15, 2015

published online

November 24, 2015
DOI http://dx.doi.org/

10.1055/s-0035-1566266. ISSN 2194-7635.

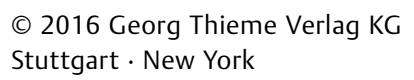

License terms

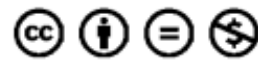




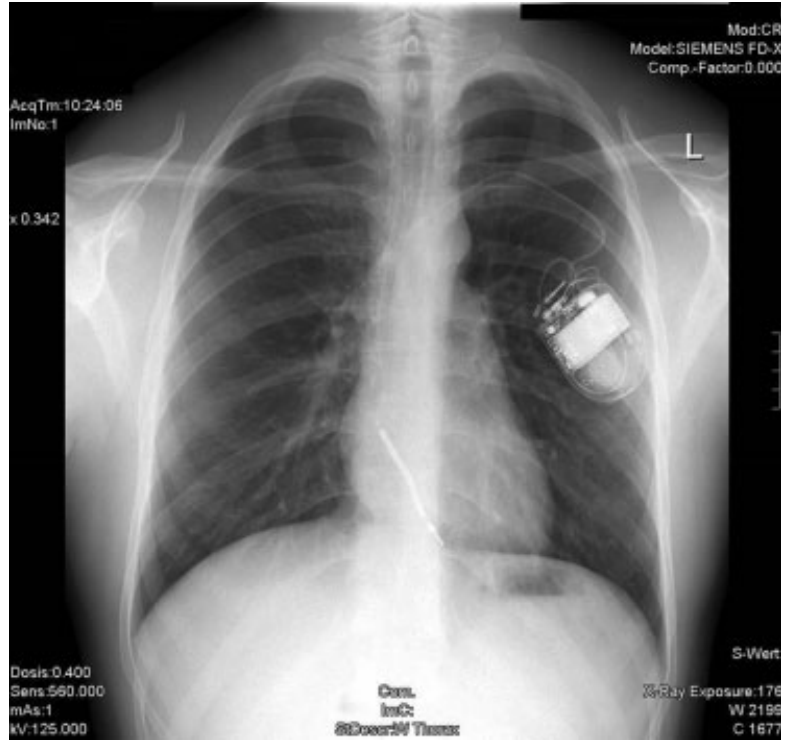

Fig. 1 Chest $X$-ray showing malfunctioning ICD lead 14 years after implantation.

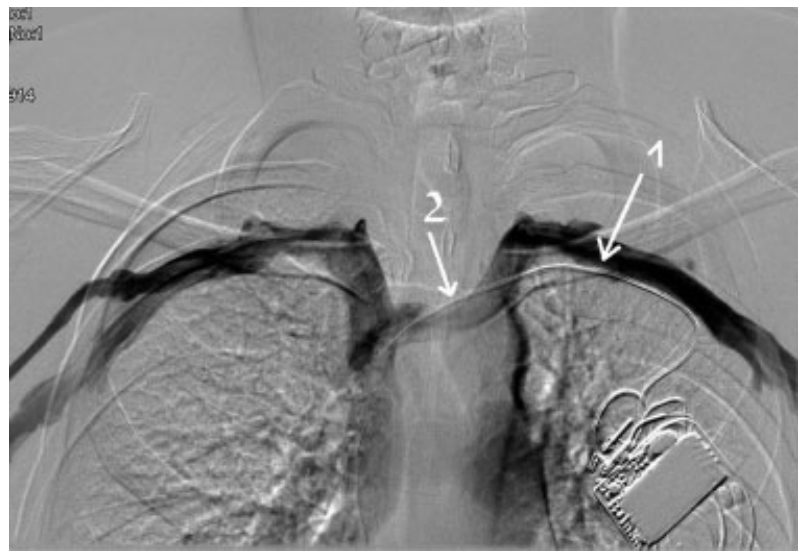

Fig. 2 Phlebography demonstrating long-range migration of the ICD lead at the site of the subclavian vein (arrow 1 ) and migration of the ICD lead at the site of the innominate vein (arrow 2).

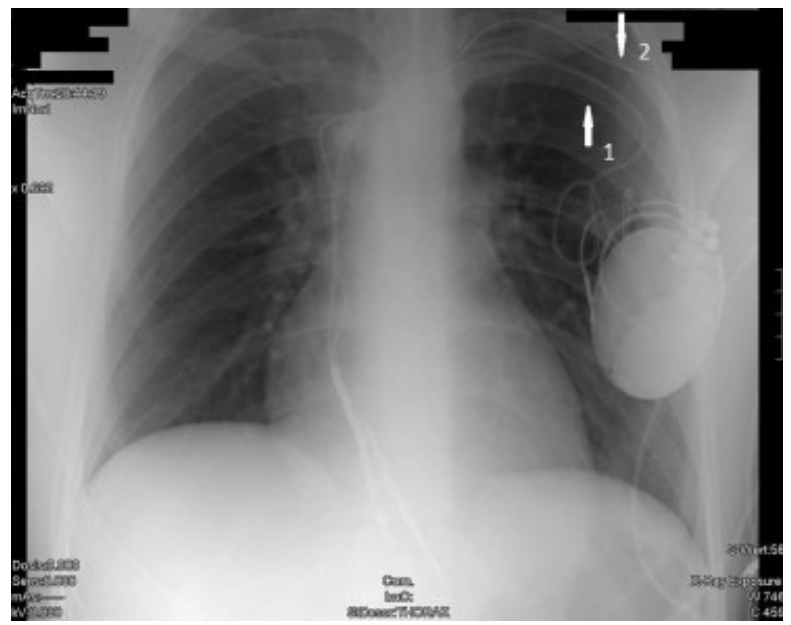

Fig. 3 Chest X-ray after ICD lead exchange; the old ICD lead (arrow 1) and the new ICD lead (arrow 2) in place. sheath, and the device was exchanged. Intraoperative testing with a 10-J safety margin was successful. After uneventful surgery, the patient was discharged home 1 day later.

The publication of medical data and images from the patient has been authorized by the patient himself.

\section{Discussion}

In this patient, an ICD lead implanted during childhood came under considerable growth-related tension, which was probably the cause for transmural migration. Relying only on the chest X-ray, replacement of the ICD lead was initially favored with removal of the malfunctioning lead, thus avoiding a nonfunctional lead in situ, particularly in this 21-year-old man. Although the indications for lead extraction are well defined in the Heart Rhythm Society guidelines of $2009,{ }^{6}$ the risk/benefit ratio, respectively, advantages of lead extractions in case of Class II $(\mathrm{a} / \mathrm{b})$ indications, and the profit of timely lead extraction in case of technical lead malfunctions without guideline-based indication are yet frequently discussed.

In general, several methods for lead extraction can be employed depending on the indication, time of lead implantation, and the clinical conditions. Leads which had been implanted less than 1 year ago can usually be retrieved by simple traction. In contrast, extraction of older leads usually needs refined techniques including sheaths in combination with a nonlocking or a locking stylet, powered sheaths such as electrosurgical dissection sheaths, mechanical dilator sheaths, and Excimer laser sheaths. ${ }^{7-9}$ All these tools are appropriate, but they are also associated with dreadful complications such as perforation of central veins and cardiac cavities. ${ }^{4,8}$ Therefore, close attention should be paid to these complications and suitable diagnostic preparations prior to surgery are mandatory to avoid them. For the sake of the patients, lead extraction including powered extraction tools should be performed in specialized centers with adequate experience in lead extraction and complication management. It is reasonable to perform these interventions in a cardiac surgery operation theater, or cardiac surgery should be promptly available.

Externalization and migration of lead conductors in the area of the right atrium, superior cava, and innominate vein have been published, which recently applied to Riata, Kentrox, and Lenox ICD leads (Saint Jude Medical ICD leads Riata 8 French and Riata ST 7 French models, St. Jude Medical, Saint Paul, Minnesota, United States, Biotronic ICD leads Kentrox, BIOTRONIK SE \& Co. KG, Berlin, Germany and Biotronic ICD leads Lenox) BIOTRONIK SE \& Co. KG. ${ }^{10-12}$ In the context of these ICD leads, the term "transmural" concerned the integrity of the lead itself-an extravascular or extracardiac migration of leads or parts of a lead have not been described.

Multiple cases of transmural lead migration have been reported; however, most of them describe a tip penetration into the myocardium. ${ }^{5,13}$ Computed tomography well documents the penetrations of the lead tips. Extravascular location of an ICD lead at the site of the innominate vein has been described by Marrazzo et al. ${ }^{14}$ So far, true transmural migration of a temporary epicardial lead diagnosed by computed tomography has only been reported once. ${ }^{15}$ We omitted 
computed tomography to limit radiation exposure. The question as to whether transmural migration is present was adequately answered by phlebography, which presented a long-segment transmural migration of the ICD lead. Certainly, a cephalic vein cutdown could have ruled out any inappropriate lead course in our patient. Marrazzo et al's case showed an extravascular location of an entrapped part of a lead due to the unintentional percutaneous puncture of the innominate vein after piercing the subclavian vein. ${ }^{14}$ Yet the course of the old lead topographically compared with the new lead may as well argue against any inappropriate lead course in our patient. Even more, rather the subclavian vein itself has migrated with growth of our patient and has left the stretched ICD lead behind.

Kennergren et al published their single-center experience with a failure rate of $0.7 \%$, a major complication rate of $0.9 \%$, and no extraction-related mortality in more than 1,000 leads, thus indicating that the paradigm of abandoning redundant leads, instead of removing them, should be reconsidered. ${ }^{1}$ Yet, a long-segment transmural lead migration in a subclavian or innominate vein as in our case bears incalculable bleeding risks following vessel perforation.

Other arguments favoring lead extraction are venous obstruction and electrical interference. Venous obstruction as a consequence of superfluous leads is speculative, and at least a couple of studies have argued against an increased risk of venous occlusion with multiple leads. ${ }^{16,17}$ The fear of electrical interference is unsubstantiated. ${ }^{18}$ Having no substantial argument to remove the ICD lead in our patient, we decided to leave the malfunctioning lead in situ. Intraoperative testing of the new device with a 10-J safety margin was successful.

\section{Conclusion}

Long-segment transmural migration of pacemaker and ICD leads may occur in patients growing up. Patients scheduled for lead extraction should be carefully selected, missing investigations should be adequate completed, obscurities eradicated, guidelines reviewed, and risk/benefit ratio should be critically checked before performing lead extraction. This should especially be done in patients who received cardiac implantable electronic devices in childhood.

\section{References}

1 Kennergren C, Bjurman C, Wiklund R, Gäbel J. A single-centre experience of over one thousand lead extractions. Europace 2009; 11(5):612-617

2 Deharo JC, Bongiorni MG, Rozkovec A, et al; European Heart Rhythm Association. Pathways for training and accreditation for transvenous lead extraction: a European Heart Rhythm Association position paper. Europace 2012;14(1):124-134

3 Jones SO IV, Eckart RE, Albert CM, Epstein LM. Large, single-center, single-operator experience with transvenous lead extraction: outcomes and changing indications. Heart Rhythm 2008;5(4): 520-525

4 Gould PA, Krahn AD; Canadian Heart Rhythm Society Working Group on Device Advisories. Complications associated with implantable cardioverter-defibrillator replacement in response to device advisories. JAMA 2006;295(16):1907-1911

5 Lewis RK, Pokorney SD, Greenfield RA, et al. Preprocedural ECGgated computed tomography for prevention of complications during lead extraction. Pacing Clin Electrophysiol 2014;37(10): 1297-1305

6 Wilkoff BL, Love CJ, Byrd CL, et al; Heart Rhythm Society; American Heart Association. Transvenous lead extraction: Heart Rhythm Society expert consensus on facilities, training, indications, and patient management: this document was endorsed by the American Heart Association (AHA). Heart Rhythm 2009;6(7):1085-1104

7 Field ME, Jones SO, Epstein LM. How to select patients for lead extraction. Heart Rhythm 2007;4(7):978-985

8 Maytin M, Epstein LM. The challenges of transvenous lead extraction. Heart 2011;97(5):425-434

9 Buiten MS, van der Heijden AC, Schalij MJ, van Erven L. How adequate are the current methods of lead extraction? A review of the efficiency and safety of transvenous lead extraction methods. Europace 2015;17(5):689-700

10 Maytin M, Wilkoff BL, Brunner M, et al. Multicenter experience with extraction of the Riata/Riata ST ICD lead. Heart Rhythm 2014; 11(9):1613-1618

11 Abi-Saleh B, Refaat MM, Khoury M, Wilkoff B. Conductor externalization of the Biotronik Kentrox internal cardioverter-defibrillator lead: the tip of another iceberg? Heart Rhythm 2014;11(9): $1648-1650$

12 Manfredi JA, Smithgall SM, Kircher CM, Lollis MA. Insulation failure with externalized conductor of a Linox SD lead: a case report. J Cardiovasc Electrophysiol 2014;25(4):440-441

13 Henrikson CA, Leng CT, Yuh DD, Brinker JA. Computed tomography to assess possible cardiac lead perforation. Pacing Clin Electrophysiol 2006;29(5):509-511

14 Marrazzo N, Ugolotti U, Quinto Villani G, Groppi F, Castellini P, Capucci A. Endocardial defibrillation lead extraction: an unusual case of entrapment. Pacing Clin Electrophysiol 2003;26(10): 2036-2038

15 Hong SN, Rosenzweig B, Crooke GA, Kronzon I, Srichai MB. Inside and out: an epicardial lead gone astray. Tex Heart Inst J 2011; 38(2):204-205

16 de Cock CC, Vinkers M, Van Campe LC, Verhorst PM, Visser CA. Long-term outcome of patients with multiple $(>$ or $=3$ ) noninfected transvenous leads: a clinical and echocardiographic study. Pacing Clin Electrophysiol 2000;23(4, Pt 1):423-426

17 van Rooden CJ, Molhoek SG, Rosendaal FR, Schalij MJ, Meinders AE, Huisman MV. Incidence and risk factors of early venous thrombosis associated with permanent pacemaker leads. J Cardiovasc Electrophysiol 2004;15(11):1258-1262

18 Glikson M, Suleiman M, Luria DM, et al. Do abandoned leads pose risk to implantable cardioverter-defibrillator patients? Heart Rhythm 2009;6(1):65-68 